\title{
Comunicación mediática y noticias regionales. La televisión pública en Río Negro
}

\section{Media communication and regional news. Public television in Rio Negro}

\author{
Pablo Schleifer ${ }^{1}$ \\ Recibido: 01-08-2017 - Aceptado: 20 -12-2017 \\ DOI: https://doi.org/10.26441/RC17.1-2018-A9
}

RESUMEN: El objetivo del presente artículo es comprender el sentido de las políticas de comunicación respecto del canal provincial de televisión por parte de los gobiernos de la provincia de Río Negro desde la finalización de la Unión Transitoria de Empresas con Artear hasta 2015. En efecto, en 2009 se da por finalizado ese vínculo y comienza un proceso de re-estatización de la emisora que pondrá de manifiesto las tensiones entre la constitución de un servicio público o la utilización gubernamental del único canal de televisión de aire. En este marco, analizamos esas políticas en función de tres dimensiones: la constitución de los órganos de dirección, la programación y la financiación.

Palabras clave: estado; políticas de comunicación; televisión pública.

ABSTRACT: The objective of the present article is to understand the meaning of communication policies regarding the state television channel by the governments of the province Rio Negro since the end of the Transition Union of Companies with Artear until 2015. In effect, in 2009 this link is terminated and a process of re-nacionalization of the station begins which will highlight the tensions between the constitution of a public service or the government's use of the only air television channel. In this context, we analyze these policies according to three dimensions: the constitution of the control and management organs, the programming and the financing.

Key words: state; communications policies; public television.

1 Pablo Schleifer es Licenciado en Ciencias de la Comunicación (UBA), Magíster en Ciencias Sociales y Humanidades con Mención en Sociología y doctorando en etapa de tesis en Ciencias Sociales y Humanas en la Universidad Nacional de Quilmes. Es Profesor Adjunto en la Universidad Nacional del Comahue (Argentina). pablo_schleifer@yahoo.com.ar, https://orcid.org/0000-0002-7050-1391 


\section{Introducción}

En gran parte de la provincia de Río Negro, ubicada en el norte de la patagonia argentina, con una extensión de $203.013 \mathrm{~km}^{2}$ y una población que apenas supera los 600.000 habitantes, los ciudadanos no pueden acceder gratuitamente a más señales de televisión que la que brinda Canal 10, señal gestionada actualmente por el gobierno provincial. En algunos barrios de algunas ciudades puede captarse Canal 7 de la vecina provincia del Neuquén y/o Canal 7 de Capital Federal; las opciones, luego, son solo de pago y en solo uno de los prestadores de servicios de televisión por suscripción².

En este sentido, la función social y comunicacional de Canal 10 cobra relevancia en por lo menos tres aspectos: a) como medio para ampliar el acceso a la información tanto de carácter nacional e internacional como, fundamentalmente, local y regional; b) en la ampliación y resignificación del espacio público a través de políticas de producción, de programación y de fomento de los contenidos locales y regionales y; c) en la generación de trabajos propiamente periodísticos y comunicacionales para periodistas y comunicadores de la región que, asimismo, permitan construir y visibilizar temas, asuntos, cuestiones de interés regional (y, por lo tanto, que no invisibilicen los conflictos locales y regionales) tanto como difundir el arte, las culturas y el entretenimiento local.

En este marco, nos preguntamos por el sentido de las políticas de comunicación respecto del Canal que han construido los gobiernos provinciales desde la re-estatización en 2009. Pues, postulamos que el sentido de esa intervención puede reconstruirse al analizar, por un lado, la constitución del Directorio del canal y el grado de relación o sujeción con el Poder Ejecutivo Provincial (en adelante PEP); por otro lado, mediante el análisis de la programación y de las políticas de impulso a la diversidad y pluralidad; y, finalmente, al analizar las formas de financiamiento y los lazos económicos con el PEP y con el mercado privado de la publicidad zonal.

Con este cometido, en el primer apartado explicitamos el Marco Teórico y la estrategia metodológica con la que venimos trabajando desde el proyecto Conflictividad social, Estado y políticas públicas en el Alto Valle de Río Negro (2007-2015) ${ }^{3}$; en un segundo momento, nos detendremos en la historia del Canal desde su surgimiento para, en el tercer apartado, profundizar en las dimensiones explicitadas en el párrafo anterior. Finalmente, en las Reflexiones finales intentaremos pensar relacionalmente esas dimensiones.

2 La provincia de Río Negro limita al oeste con la provincia del Neuquén; Canal 7 de esa provincia puede sintonizarse por aire en la región del Alto Valle, un corredor de unos 90 km que condensan más del 50\% de los habitantes de Río Negro.

3 Proyecto D-103 de la Facultad de Derecho y Ciencias Sociales, Universidad Nacional del Comahue, dirigido por la Mgr. María Mazzoni. 


\section{Perspectiva de análisis}

Postulamos la existencia de una "causalidad estructural" que explica la relación entre la conflictividad social como constitutiva del modelo de acumulación capitalista y las políticas públicas que los Estados capitalistas impulsan. Pues el Estado constituye un actor con un alto grado de centralidad basada, entre otras cosas, en la concentración de la administración, de la fijación de políticas públicas y en el monopolio del uso legítimo de la fuerza física y simbólica (Bourdieu, 2007; García Linera, 2008; Gramsci, 1984); en este sentido, cada vez que el Estado establece una política contribuye a la materialización de un orden, toma posición sobre los conflictos y universaliza ese posicionamiento (Bourdieu, 2007; Dos Santos, 2011; García Linera, 2008; Gramsci, 1984; Marini, 1997; Marx, 2010).

Así, las políticas del Estado provincial, en tanto Estado capitalista, tienden a garantizar el modelo de acumulación económica y, en este marco, la re-estatización del canal público de televisión constituye un hecho preponderante en las disputas del sentido. Pues en tanto forma específicamente capitalista de producción cultural, la Industria Cultural, al decir de César Bolaño (2015: 71), tiene una función de mediación entre el poder político y/o el poder económico y los públicos; mediación entendida desde la perspectiva de la "contradicción entre control y cambio, dominación y apropiación cultural, subsunción y resistencia, manipulación y praxis social liberadora"4.
Efectivamente, puesto que los medios cuentan con una formidable eficacia simbólica en la construcción y circulación de puntos de vista sobre el mundo social; que contribuyen a la formación de "opinión pública" (Champagne, 1990), a la valoración de los hechos, sucesos o fenómenos sociales y que cuentan con un enorme poder para visibilizar u obstaculizar el surgimiento mediático (social) de los asuntos sociales (Bourdieu, 2000; Champagne 2007); la pregunta que aquí nos hacemos es por la función y las formas de organización y de funcionamiento de la emisora gestionada por el Estado en el sentido de dilucidar la direccionalidad de esa política.

De esta forma, "las políticas de comunicación se constituyen por el conjunto de decisiones que van perfilando la conformación de las Industrias Culturales, la estructura económica que las sustenta y los modos de participación de los actores sociales y de la ciudadanía" (Uranga, 2006: 8). Respecto de los medios públicos señala Omar Rincón (2014 citado en Becerra, 2015) que lo que define a los medios públicos es que son (o debieran ser) lo que no son los medios privados comerciales. Pues los medios públicos lejos de orientarse y organizarse en función del axioma según el cual "lo que sirve es lo que vale, es decir lo que vende", de atar su producción y programación a la lógica de la ganancia, del rating y de la competitividad, organizan (o deberían organizar) su funcionamiento en función de la diversidad, del pluralismo 
social, ideológico y político (MartinBarbero, Rey y Rincón, 2000), de la cobertura universal.

Así, para ser un verdadero servicio público, la comunicación audiovisual debe intentar cumplir los siguientes requisitos descritos por Antonio Pasquali (1991) hace ya 25 años: ser independiente del Poder Ejecutivo, financiarse con fondos del erario público y no depender de la pauta publicitaria, ser participativa, de calidad, descentralizada y complementaria; en efecto, se trata de una perspectiva que supone la ampliación del espacio público, del debate social mediante la participación activa y no gubernamentalizada, como sugieren los acuerdos del Primer Foro Mundial de Medios Públicos (desarrollado en 2011 en Guadalajara): contenidos producidos por los más diversos sectores de la ciudadanía para lo cual es menester una política activa de impulso a la producción audiovisual independiente y alternativa.

Ahora bien, no pretendemos establecer "un listado de características ideales" sino analizar lo que realmente pasa (Becerra et. al., 2012) en un caso particular; pues pretendemos contrastar esas dimensiones, en tanto indicadores de la direccionalidad de las políticas de comunicación provinciales, con la realidad empírica de un medio gestionado por el Estado en un espacio comunicacional periférico del norte de la patagonia argentina. Con este cometido, desde el plano metodológico y para reconstruir la trama de las políticas, trabajamos principal- mente con datos secundarios provenientes de organismos gubernamentales y no gubernamentales, con la normativa vigente, con artículos académicos y noticias periodísticas y con entrevistas a funcionarios, periodistas y productores realizadas entre 2009 y 2015.

\section{Canal 10, surgimiento y desarrollo ${ }^{5}$}

Canal 10 comienza a emitir el 20 de marzo de 1982 luego de la adjudicación de la frecuencia y de la construcción en la zona norte de la ciudad de General Roca de un edificio de poco más de 850 $m t^{2}$ cubiertos de superficie. Tres años más tarde, la Legislatura de la provincia sanciona la Ley 1952 mediante la cual autorizaba en el artículo $1^{\circ}$ al PEP a "constituir Radio Televisión de Río Negro, Sociedad Del Estado LU 92 Canal 10 (R.T.R.N.), conforme al régimen de la Ley Nacional № 20.705”. El gobierno de Álvarez Guerrero (19831987) pretendía, en palabras de un funcionario del área de comunicación de aquella época entrevistado:

...crear un centro público de producción y distribución (...) Ese centro debía atender la necesidades básicas de todas las radios y canales en la provincia (material, archivo, capacitación, intercambio, etc), con la posibilidad de centros rotativos de noticias. Queríamos evitar el localismo, y que el "canal 10" (una identificación técnica, es decir el nombre del estacionamiento) no fuera el "canal de Roca" sino que tuviera un soporte en esa ciudad.

5 Los avances de este apartado fueron discutidos en el XX Jornadas Nacionales de Investigadores en Comunicación desarrollado en 2016 en la UPSJB. 
Se procuraba establecer un canal abierto, público y plural que tendría por "objeto principal la prestación y explotación del servicio de radiodifusión y de televisión, la producción y emisión de programas, así como la realización de toda otra actividad vinculada directa $o$ indirectamente con la radio teledifusión" $\left(\operatorname{art} .2^{\circ}\right)$. Con ese cometido, se debería establecer un "Consejo Asesor Editorial, integrado por representantes de los diversos sectores sociales, de la actividad económica, cultural, política y científica de la comunidad rionegrina, que tendrá como función asesorar al directorio sobre la programación y los contenidos emitidos por la Sociedad del Estado, atendiendo especialmente a la integración cultural de la provincia, al desarrollo humano y a la plena vigencia de las libertades de expresión e información, como asimismo la consolidación de las instituciones democráticas" (art. $\left.4^{\circ}\right)$. Es decir, si bien la conformación del directorio quedaba a disposición del PEP, la conformación del Consejo Asesor Editorial generaba una instancia participativa y plural para la definición de la producción y de los contenidos; no obstante, ese Consejo nunca se formalizó y, por el contrario,

... la tendencia a subordinar el canal a los caprichos de funcionarios se instaló definitivamente pues lo que se interpuso (entre el espíritu de la Ley y su aplicación) diría que fue la mediocridad, la falta de compromiso y de comprensión de muchos sectores de comprender las posibilidades de un sistema regional. De ahí a la UTE con ARTEAR hubo un trecho mínimo.
(Entrevista personal a un funcionario del área comunicacional del gobierno de Álvarez Guerrero).

Efectivamente, los principios que dieron origen a la Ley 1952 fueron relegados al mismo tiempo que desde el gobierno nacional de Carlos Menem (1989-1995 y 1995-1999) se abandona toda pretensión de constituir, mantener o profundizar servicios públicos gestionados por el Estado y, en lo que respecta al sector de las radiodifusiones, se inicia un proceso de re-regulación "generando un volumen de dispositivos legales, en muchos casos mayor que los previos, destinados a establecer reglas de juego acordes a los intereses de los grupos oligopólicos" (Mastrini y Mestman, 1995: 2). Así, con medidas como la Ley 23696 de Reforma del Estado, se posibilita e impulsa la privatización de las empresas públicas, entre ellas las señales de radio y televisión y la conformación de multimedios que fueron adquiriendo o bien apoderándose de la programación (vía venta de contenidos y del establecimiento de redes transitorias o permanentes) de gran parte de las señales del "interior" del país.

En concordancia con el plano nacional, en la provincia de Río Negro se profundiza a partir de 1995 un "ajuste neoliberal tardío” (Camino Vela, 2014); pues el gobernador Pablo Verani (19951999 y 1999-2003) emprendió la privatización de empresas y entes fundamentales como el Banco Provincia de Río Negro (BPRN), Servicios Aéreos Patagónicos S.E. (SAPSE), Hierro Patagónico S.A. (HIPARSA), Energía 
Río Negro S.E. (ENRE), al mismo tiempo que se cedió en concesión por un plazo de 30 años la operación del Puerto de San Antonio Este.

Es en ese contexto que el 29 de diciembre de 1998 la Legislatura provincial sanciona la Ley 3276 mediante la cual se ratifica el contrato de conformación de una Unión Transitoria de Empresas entre ARTEAR S.A. ${ }^{6}$ y R.T.R.N. S.E. LU92 Canal 10, firmado por el gobierno rionegrino y los empresarios quince días antes. Esta decisión política significa el entierro de los principios que dieron origen a R.T.R.N. y de un instrumento audiovisual para visibilizar las realidades regionales.

Así, entre las premisas comerciales que las partes acordaron figuraba la compra por parte de R.T.R.N a ARTEAR de la programación (Cláusula 6.2 a. I); la reserva dentro de la grilla de "hasta catorce (14) horas semanales destinadas a producciones regionales, de las cuales al menos dos (2) serán incluidas en horario central" (Cláusula 7.4); la obligación de incluir una hora diaria de información regional, dividida en dos segmentos de media hora cada uno, al tiempo que se especifica que "El Consejo de Administración tendrá la absoluta dirección de la editorial de los temas de incumbencia regional" (Cláusula 7.6). La participación en las ganancias que la U.T.E. pudiera generar se fija en un $85 \%$ para ARTEAR y en un $15 \%$ para R.T.R.N. (Cláusula 8).
El objeto de la U.T.E., que tenía un plazo máximo de duración de 10 años (Cláusula $2^{\circ}$ ), era "el desarrollo de un proyecto de producción y comercialización de contenidos y espacios de publicidad en común para el crecimiento del servicio de televisión abierta en el interior de la provincia” (Cláusula $1^{\circ}$ ). Nada de esto se cumplió; pues la forma de organización que primo por sobre cualquier pretensión de establecer un canal representativo y regional, fue el modelo de negocios propio de las emisoras privadas centrales y para un selecto y acotado grupo de productores privados locales.

En este sentido, la centralización geográfica de la producción de contenidos que, como sostienen Becerra y Mastrini (2011), constituye una de las principales características del sistema de medios de Argentina e implica que los contenidos se producen mayoritariamente en la zona de Buenos Aires y luego se reproducen en cadena al resto del país, impacta debilitando el espacio público (Becerra y Mastrini, 2009) y reproduciendo la circulación centro-periferia. En efecto, señalan Mastrini y Aguerre (2007), que se ha definido históricamente que la forma de garantizar el pluralismo es a través de la diversidad de medios, de múltiples voces y de diferentes expresiones políticas y que, por ello, el derecho a recibir e impartir información no puede quedar circunscripto a establecer

6 Empresa del Grupo Clarín, uno de los principales oligopolios de la comunicación en Argentina y América Latina (Becerra y Mastrini, 2009; Getino, 2008). 
una estructura de propiedad no oligopólica sino que también debe garantizarse la multiplicidad de contenidos. En este marco, los espacios para la producción comunicacional y periodística se desprenden no de la cantidad de medios de comunicación sino de los espacios destinados a esa producción en los medios vigentes.

La U.T.E. no incentivó la producción local, independiente y plural; al contrario, como afirmaba el interventor por parte de la provincia Alejando Kunz, "las producciones regionales corresponden a proyectos privados que compran el espacio y para el informativo se contrató a una productora" (Diario Río Negro, 21/09/04). Vía satélite, la casi totalidad de las horas de emisión llegaban desde Buenos Aires al tiempo que el canal era vaciado no solo de contenidos regionales sino de equipamiento y "Los trabajadores están muy disconformes porque sienten que hay maltrato laboral. Fueron formados para trabajar en canal 10 y los tienen 8 horas sin ninguna función importante. Algunos sólo mencionan las farmacias de turno", comentaba al Diario La Nueva Provincia la legisladora Magdalena Odarda ( $L a$ Nueva Provincia, 16/11/04).

Hacia el año 2004 el abandono era tan notorio que, producto de una deuda con Telefónica de 1.500 .000 de pesos, el canal había dejado de ser transmitido por parte de sus repetidoras al punto de que, por ejemplo, no podía verse en la capital de la provincia. Más de 5000 rionegrinos, "acompañados por la Legisladora Provincial Magdalena Odarda, presentaron un recurso de amparo colectivo en el Superior Tribunal de Justicia de la Provincia, con el fin de defender el canal 10 y permitir que sus repetidoras, hagan llegar la señal del canal estatal rionegrino a todos los puntos de Río Negro" (Diario La Palabra, 26/11/08). Además, requerían la conformación del Consejo Asesor Editorial, la formación de un Directorio plural, la transmisión de debates públicos y mantener el sistema de medios públicos fuera del control de los medios privados.

\subsection{El período 2009-2015, dos gobier- nos el mismo sentido político}

En marzo de 2009, apenas antes de la finalización del contrato entre R.T.R.N y ARTEAR, en plena discusión nacional por la derogación del decreto-ley 22285 y la sanción de una nueva Ley de Servicios de Comunicación Audiovisual, con cierto grado de presión social, política y sindical para retomar el control sobre la emisora, Canal 10 vuelve a ser gestionado por el Estado provincial. El gobernador Miguel Saíz (2003 - 2007 y 2007-2011) reivindicaba la necesidad de un sistema de medios "moderno, plural y democrático al servicio de los rionegrinos" y afirmaba que la recuperación del canal "no se limita a su señal, edificios y bienes materiales sino que debe ampliarse al diseño de contenidos que muestren y expresen la cultura de la provincia y de su gente" (Diario Río Negro, 03/03/09).

En este marco, cobra relevancia el análisis de las políticas que fueron tomando respecto de la emisora tanto el gobernador radical como su sucesor 
Alberto Weretilneck (2012-2015 $)^{7}$; como veremos, ese análisis no denota sino continuidad: dos expresiones político-partidarias, una misma política de comunicación audiovisual.

\subsubsection{La dirección del canal, el con- trol político}

Como afirman Becerra et. al. (2012: 117), "los poderes públicos tienen una fuerte tentación de control" sobre los medios en general y los gestionados por el Estado (o el gobierno) en particular. Pues el poder de controlar la producción y distribución de mensajes, más aún cuando en gran parte de la provincia la única posibilidad para los ciudadanos de acceder a información audiovisual local y regional (en los otros lugares, la segunda posibilidad es de pago a través del canal local del cable) es a través de Canal 10, constituye una invariante en los gobiernos provinciales. En este sentido, si durante la U.T.E con Artear el gobierno de turno había cedido todo menos el control de los dos bloques de 30 minutos diarios de noticias; una vez recuperada la gestión de la emisora el control se volvió total sobre la totalidad de la programación.

En efecto, el vacío normativo respecto de los órganos de control o, en otros términos, la inexistencia de dichos órganos, posibilitó que rápidamente, sin iniciar procesos de consulta o de participación, el gobierno de Miguel Saiz designara a las autoridades del Canal y al Jefe de Noticias sin conformar el Consejo Asesor Editorial. En este sentido, el nombramiento del Directorio en pleno y del Jefe de Noticias por parte del PEP no significa otra cosa que la inscripción del canal como un medio gubernamental más que como estatal, público y pluriparticipativo. Puesto que responde y depende directamente del PEP, desde donde se puede direccionar vía línea editorial el tratamiento de la conflictividad social, se torna una cuestión medular analizar el funcionamiento del canal en virtud, como vimos más arriba, de su función de mediación entre el poder político y los públicos. Por ejemplo, desde la dirigencia gremial se ha cuestionado reiteradamente la política provincial con respecto al canal pues como afirmaba el Secretario General de ATE Río Negro, Rodolfo Aguiar, "creemos que un medio sostenido con el aporte de todos los ciudadanos no puede censurar ciertos reclamos gremiales y sociales" (Agencia Digital de Noticias, 2/05/14).

De esta forma, como se observa en el cuadro 1, durante los dos últimos años del gobierno de Miguel Saiz se conformó un directorio que respondía íntegramente al partido de gobierno y se designó como Jefe de

7 El 10 de diciembre de 2011 asumió la Alianza Frente para la Victoria, conformada por el Partido Justicialista y el Frente Grande; el $1^{\circ}$ de enero de 2012 el gobernador Carlos Soria fue asesinado y quedo al frente del PEP el vicegobernador Weretilneck. 
Noticias a Mario González. El enlace entre la gestión de Canal 10 y el gobierno de la provincia se constituía a través de la Secretaría de Comunicación; el secretario Claudio Mozzoni ocupaba al mismo tiempo el cargo de vice-presidente de R.T.R.N Canal 10 S.E.; "(la linea editorial) dependía en general de la Secretaría de Comunicación pero no teníamos un lineamiento; podía tener un lineamiento el noticiero pero nunca tuve un llamado del gobernador o de un ministro", afirmaba el Gerente General entre 2009 y 2011 , Pablo Schapira, en entrevista personal. Es que las presiones indirectas, incorporadas por cuerpo, aprehendidas en la práctica (del tipo "los jefes son ellos") o, en otros términos, el conocimiento práctico de las reglas de juego, de lo posible de hacer y decir y de lo imposible de hacer y decir, pueden volver redundante y hasta contraproducente cualquier atisbo de censura o, incluso, de lineamiento directo; pues como explica un periodista entrevistado:

La línea editorial determina que es importante y que no, (...) A partir de ahí, gran parte de la noticia la determina la línea editorial, determinando por ejemplo a que fuentes va a consultar. Pero la mayoría de los casos esto se da por criterios personales, no es que hay instancias de reunión donde se determina la línea editorial, el propio periodista por conocimiento previo del medio recorta de su agenda de temas aquellos hechos que suelen ser los que ese medio "sigue", y en esa selección hace un recorte. Lo mismo la perspectiva que se le da al tema, desde donde se lo aborda.

Tras las elecciones de 2011 comienza un período de quiebre en la dinámica provincial puesto que luego de 28 años de gobiernos de la Unión Cívica Radical, la Alianza Frente para la Victoria, conformada por el Partido Justicialista y el Frente Grande, accede al gobierno provincial. Una vez en el poder, el gobernador Carlos Soria ubico en el manejo del Canal a sus funcionarios más cercanos, los mismos que durante sus 8 años como intendente de la ciudad de General Roca habían estado al frente de la cuestión comunicacional municipal. Así, se designó como presidente a Julian Gohinex y como vice-presidenta a Victoria Argañaraz; como directora a Laura Tappata y como director suplente a Federico Ambroggio; la dirección de las noticias quedo a cargo de la periodista Marcia Cide.

Esta conformación del Directorio, dictada por el PEP sin consultas y sin constituir el Consejo Asesor, permaneció en funciones hasta que el gobernador Weretilneck en abril de 2014 designó, nuevamente a disposición de las necesidades del Ejecutivo, un nuevo directorio con funcionarios afines: así se designó al intendente de Contralmirante Cordero, Fabián Galli, como Presidente y se dispuso la dirección de la programación y de las noticias en manos de Omar Fuentes, un periodista de la localidad de Cipolletti (la misma de la cual había sido dos veces intendente el gobernador). 
Cuadro 1. Dirección del Canal

\begin{tabular}{|l|c|c|c|}
\hline Dimensiones/gobierno & Saiz & Soria & Weretilneck \\
\hline Directorio & Nombrado por PEP & Nombrado por PEP & Nombrado por PEP \\
\hline Gerencia Noticias & Nombrado por PEP & Nombrado por PEP & Nombrado por PEP \\
\hline Consejo Asesor & NO & NO & NO \\
\hline
\end{tabular}

Fuente: elaboración propia

Como vemos, independientemente del signo político de las administraciones provinciales, la estrategia respecto del Canal ha sido siempre la misma: controlar su funcionamiento y la dirección de la producción de noticias. En este sentido, el grado de sujeción con el Ejecutivo provincial es muestra de la falta de independencia editorial o, en otros términos, de una política de direccionamiento editorial del canal en función de los intereses del gobierno de turno.

\subsubsection{La programación, el control ideológico}

Si bien, como vimos, la ruptura de la U.T.E. fue presentada como un avance en la democratización de los medios, como una posibilidad de construir un medio plural y diverso, lo cierto es que tampoco desde el plano de la programación se persiguió aquel objetivo. Pues si como afirman Jesús Martín Barbero, Germán Rey y Omar Rincón, la televisión pública tiene como principal objetivo no solo interpelar al ciudadano sino contribuir a la "construcción del espacio público en cuanto escenario de comunicación y diálogo entre los diversos actores sociales y las diferentes comunidades culturales" (2000: 51); al mismo tiempo los medios locales son, al decir de Rosa María Alfaro (2005), el principal canal de información mediante el cual los miembros de una ciudad se enteran de lo que allí sucede. De ahí la necesidad de pluralidad en la organización de las emisoras de gestión estatal y de diversidad en la política de producción, de programación y de fomento de contenidos locales $y$ regionales.

No obstante, todos los gobiernos provinciales posteriores a la recuperación de la gestión del Canal mantuvieron la misma política de programación basada en tres pilares medulares que traslucen una concepción de comunicación y una forma de uso del canal. En primer lugar, se refrendó un nuevo contrato de explotación comercial con el Grupo Clarín, al cual se le compra gran parte de la programación de Canal 13 de Capital Federal. Los horarios centrales de la grilla de programación quedaron reservados para la retransmisión en vivo de la programación del canal de Buenos Aires, es decir que el segmento central de la grilla es producido y transmitido a larga distancia obturando esos espacios como espacios para la producción local y regional. 
Como consecuencia directa del punto anterior, los productos comunicacionales locales y regionales no noticiosos quedan reducidos a horarios marginales: de lunes a viernes, de 14 a 15-16 hs. y a los fines de semana. La producción de esos programas es en gran parte del mismo Canal, sea directamente o en coproducción con productoras locales allegadas o instituciones de la zona: "el contenido del canal está compuesto por Artear, el Bacua, canal encuentro y las pocas producciones regionales que salen de algún convenio como por ejemplo con el Iupa o los clubes Cipolletti y Deportivo Roca (...) si queres como independiente producir tu programa te cobran el espacio y una parte de la publicidad: es insostenible" (entrevista personal a un ex productor del Canal).

Así, las gestiones del Canal han carecido completamente de políticas de im- pulso y desarrollo de la producción local y regional de contenidos y, a la inversa, han desarrollado una estrategia sostenida, independientemente del color político del gobierno de turno, de situar al Canal bajo el control absoluto de las autoridades provinciales. En este marco, al mismo tiempo que se fue reduciendo la variedad de programas locales (de una grilla compuesta por programa de 30 minutos de 14 a 15 hs. en 2009, se pasó a una grilla en 2015 de un solo programa de 14 a 16 hs.), como se observa en el cuadro 2, se fue acrecentando la cantidad de espacio para el noticiero (vía Titulares a las 7, a las 8 y a las 9 de la mañana por ejemplo). Pues "la jefatura de noticias pasó a ser un cargo más político y designaron a alguien más allegado al gobernador con la consigna de llenar de noticias el canal" (periodista entrevistado).

Cuadro 2. Contenidos locales y regionales

\begin{tabular}{|l|l|l|}
\hline \multicolumn{1}{|c|}{ Horarios/gobierno } & \multicolumn{1}{|c|}{ Saiz } & \multicolumn{1}{c|}{ Weretilneck } \\
\hline Lunes a viernes & Nyc, 14 a 15 hs. & Salud, \\
& Entre corchos y corcheas, \\
Geo ambiental, & \\
& La búsqueda, \\
& El director, \\
5 respuestas, & \\
& Nación Sur, \\
& Declaración Jugada, \\
& Estación sabor & \\
& dos ediciones diarias & \\
\hline Noticiero & & $\begin{array}{l}\text { 3 ediciones de titulares por la } \\
\text { mañana y dos ediciones } \\
\text { diarias del noticiero }\end{array}$ \\
\hline
\end{tabular}




\subsubsection{El financiamiento, control eco- nómico ${ }^{8}$}

El bajo grado de independencia política debe relacionarse con la sujeción presupuestaria a los vaivenes del mercado publicitario comercial y del político. Pues al depender en gran medida de la pauta publicitaria, como en el caso de los canales privados, la programación (los programas y su contenido) y las posibilidades de diversificarla y pluralizarla, están también relacionadas con las tendencias de los anunciantes. Efectivamente, el erario público aporta al funcionamiento de la emisora el financiamiento de los recursos humanos, es decir del personal de planta y de las autoridades; el resto de los recursos económicos se gestan vía publicitaria. Para el año 2010, por ejemplo, sobre un presupuesto total de $\$ 15000000$, equivalente a 3750000 dólares, el Tesoro provincial aportaba 4.3 millones (Res. 1622 del Ministerio de Hacienda), equivalente a 1075000 dólares.

En este marco, es posible comprender más acabadamente el contrato que Canal 10 suscribe con el Grupo Clarín:

El presupuesto del canal se maneja, en gran parte, con recursos publicitarios que generamos por dos vías. Por un lado, por un acuerdo con ARTEAR que comercializa a nivel nacional la publicidad, ellos se llevan un porcentaje importante de la comercialización: se llevan casi el $50 \%$ que si alcanzan un volumen determinado puede llegar a un 55\%. Esto genera ingresos para nosotros y por el otro lado ese contenido de alto rating ayuda a vender también a los anunciantes locales; porque la realidad es también que hoy no está consolidado el modelo como para que los tipos te llamen y te digan quiero poner en Viernes cocinero (Pablo Schapira, entrevista personal).

La otra vía de venta publicitaria es a los gobiernos municipales y provinciales, especialmente de Río Negro y del Neuquén, y a los anunciantes locales y regionales. Sin embargo, según afirma Schapira, éstos prefieren anunciar en programas de Buenos Aires que en programas locales; este dato explica, en parte, la primacía en la grilla de esos programas tanto en cantidad de horas como en la centralidad de los horarios y, al mismo tiempo, pone en cuestión el objeto de un canal público y provincial: transmitir lo que vende o las culturas y las realidades locales independientemente de las tasas de ganancias.

En un Informe Oficial a la Legislatura provincial, se informa que del año 2008 al 2009 habían aumentado las horas de programación local un $11 \%$ y que se destacaba en ese proceso "un crecimiento en las producciones propias del canal y en las producciones independientes", los convenios con la TV Pública, el INCAA, Canal Encuentro y la puesta en funcionamiento de la emisora de radio (Diario Río Negro, 24/02/10). Así:

8 Los avances de este apartado fueron discutidos en el XX Jornadas Nacionales de Investigadores en Comunicación desarrollado en 2016 en la UPSJB. 
Llegamos al final de la gestión con un $55 \%$ de producción regional cuando antes estabas en el $35 \%$ y era casi todo el noticiero y programas de producción que compraban el espacio. Porque esa era una característica, antes el espacio se vendía porque había una política de generar recursos; nosotros transparentamos porque se vendía y algunos productores debían muchas cuotas y eso era una tontería; entonces nos planteamos reformular los contratos y en lugar de cobrarle lo incobrable hagamos algo que en un modelo de negocios le permita al productor generar sus recursos y una vez que cubrió sus costos, sobre el excedente, vayamos compartiendo los ingresos. Esa fue para nosotros la mejor manera de integrar la producción local (Pablo Schapira, entrevista personal).

Como se desprende de lo enunciado, no existen de parte del Estado provincial ni de la emisora políticas tendientes a ampliar y desmercantilizar la producción de contenidos locales y regionales. Impera "el modelo de negocios" por sobre el modelo de la complementariedad, la diversidad y la pluralidad. Los contenidos producidos en Buenos Aires, privados o públicos, dominan la pantalla relegando los contenidos locales al horario marginal de 14 a 15 hs, salvo el noticiero dirigido por un representante del PEP.

\section{Reflexiones finales}

No ha sido nuestra intención describir una por una la totalidad de las políticas vinculadas a lo mediático imple- mentadas por los gobiernos de la provincia de Río Negro; más bien, nos hemos abocado a intentar comprender el sentido y la direccionalidad política de las políticas relacionadas con el canal de televisión desde su re-estatización en 2009. Pues, como afirmamos en la Introducción, el Estado es un actor central que contribuye a la materialización del orden de las cosas y que, en ese sentido, cuando fija una política toma posición sobre los conflictos y universaliza ese posicionamiento. Capacidad que se multiplica al contar con la potestad de definir la línea editorial del canal público de televisión, de instituirse como árbitro en relación con la visibilidad o no de los conflictos sociales, culturales, económicos y políticos y de los distintos actores de la región. Capacidad, al mismo tiempo, de censor toda vez que la programación es definida, como decisión política, por las posibilidades de financiamiento o de compra de espacio de los productores locales y regionales.

Efectivamente, como vimos, es posible establecer cierta correspondencia entre la cesión a ARTEAR del canal y la lógica de organización y funcionamiento establecida desde la recuperación en 2009: la escasa independencia política con respecto al gobierno de turno; la limitada autarquía financiera en relación al gobierno y al mercado publicitario, lo cual limita las capacidades de impulsar, incentivar y experimentar con contenidos, problemáticas, formatos y actores sociales diversos y plurales; y la reproducción de contenidos producidos en los centros comunicacionales 
que representan solo en parte las preocupaciones y las necesidades informativas, culturales y de entretenimiento locales y regionales y que, al mismo tiempo, generan poco trabajo genuino para los trabajadores de la rama comunicacional de la región, son signos de una forma de entender la comunicación medíatica y su importancia en las sociedades actuales.

En efecto, si los medios de comunicación cumplen una función de mediación entre el poder político y económico y los públicos cabe preguntarse, entonces, qué sucede cuando el único canal de televisión de aire que puede visualizarse en todo el territorio provincial, con capacidad potencial de hacer circular las problemáticas de las diversas regiones de la provincia, las culturas y los usos, los gustos y las necesidades comunicacionales, queda sujeto directamente a las necesidades del poder político e, indirectamente, del poder económico vía financiamiento publicitario. Pues bien, podemos concluir que lejos de funcionar como un servicio público, Canal 10 funciona como un canal gubernamental atado a la lógica comercial.

Resta, sin duda, indagar en otras dimensiones de manera de dar cuenta de manera más global de la direccionalidad de las políticas provinciales, ya no solo respecto del Canal sino del campo comunicacional. En este sentido, nos proponemos indagar en próximos trabajos en dos dimensiones que parecen centrales, a saber: la política de distribución de la pauta publicitaria oficial y, por otro lado, las políticas respecto del acceso a la información. Pues, en efecto, es menester profundizar el análisis de las políticas públicas respecto del sector en función de otras variables y dimensiones que en los límites de este escrito no hemos podido abarcar pero que permitirán comprender más acabadamente el grado de centralidad de los Estados en la estructuración de los espacios comunicacionales y mediáticos periféricos.

\section{Bibliografía}

Alfaro, R. M. (2005). Politizar la ciudad desde comunicaciones ciudadanas. Diálogos de la comunicación, 65, s/n. Recuperado de http://dialogosfelafacs.net/ el 02/02/2007.

Becerra, M.; Arroyo, L.; García Castillejo, Á. y Santamaría, O. (2012). Cajas Mágicas. El renacimiento de la televisión pública en América Latina. Madrid: Editorial Tecnos.

Becerra, M. (2015). De la concentración a la convergencia. Políticas de medios en Argentina y América Latina. Buenos Aires: Paidós.

Becerra, M. y Mastrini, G. (2009). Los dueños de la palabra. Acceso, estructura y concentración de los medios en la América latina del Siglo XXI. Buenos Aires: Prometeo libros.

Becerra, M. y Mastrini, G. (2011). Transformaciones en el sistema de medios en la Argentina del siglo XXI. Working Paper, $\mathrm{N}^{\circ} 21, \mathrm{~s} / \mathrm{n}$.

Bolaño, C. (2015). Campo aberto. Para una crítica da epistemologia da comunicaçao. Aracaju: Edise. Bourdieu, P. (2000). Sobre la televisión. Barcelona: Anagrama.

Bourdieu, P. (2007). Espíritus de Estado. Génesis y estructura del campo burocrático. En 
Razones prácticas. Sobre la teoría de la acción. Barcelona: Anagrama.

Camino Vela, F. (2014). La provincia de Río Negro entre 1983 y 2003: predominio radical bajo diferentes modelos. POSTdata, n², pp.713-747.

Champagne, P. (1990). Faire l'opinion. Le nouveau jeu politique. Paris: Éditions du Minuit.

Champagne, P. (2007). La visión mediática. En P. Bourdieu (Dir.), La miseria del mundo. Buenos Aires: Fondo de Cultura Económica.

Dos Santos, T. (2011). Imperialismo y Dependencia. Caracas: Biblioteca Ayacucho de Clásicos Políticos da América Latina; Banco Central de Venezuela.

García Linera, A. (2008). El Estado en Transición. Bloque de poder y punto de bifurcación. Texto inédito.

Getino, O. (2008). El capital de la cultura. Las industrias culturales en a Argentina. Buenos Aires: Ediciones Ciccus.

Gramsci, A. (1984). Notas sobre Maquiavelo, sobre la política y sobre el Estado moderno. Buenos Aires: Nueva Visión.

Mastrini, G. y Mestman, M. (1995). ¿Desregulación o reregulación? De la derrota de las políticas a la política de las derrotas. Ponencia I Jornadas de Jóvenes Investigadores en Comunicación, Buenos Aires.

Mastrini, G. y Aguerre, C. (2007). Muchos problemas para pocas voces. La regulación de la comunicación en el siglo XXI. Diálogo político, $\mathrm{N}^{\circ} 3, \mathrm{~s} / \mathrm{n}$.

Martín-Barbero, J., Rey, G. y Rincón, O. (2000). Televisión pública, cultural, de calidad. Revista Gaceta, 47, pp.50-61.

Marx, K. (2010). Crítica de la Filosofía del Estado de Hegel. Madrid: Editorial Biblioteca Nueva. Recuperado de: http://socialismoactual.blogspot.com

Pasquali, A. (1991). El orden reina. Escritos sobre comunicaciones. Caracas: Monte Ávila Ed.

Uranga, W. (2006). Prólogo. En Mastrini, G. (Ed.), Mucho ruido, pocas leyes. Economía y políticas de comunicación en la Argentina (1920-2004). Buenos Aires: La crujía.

- Artículos periodísticos citados:

"El Canal provincial no se ve en la propia capital de Río Negro", Diario La Nueva Provincia, 16 de septiembre de 2004.

"Confesión oficial: si Canal 10 sigue con ARTEAR no sirve a la provincia", Diario Río Negro, 21 de septiembre de 2004.

“Odarda apoya a Canal 10 y Radio LU 92, Radio y Televisión Río Negro”, Diario La Palabra, 26 de noviembre de 2008.

“Canal 10 volvió a manos del Estado”, Diario Río Negro, 3 de marzo de 2009.

“Detallan gastos, planes e inversiones de Canal 10”, Diario Río Negro, 2 de febrero de 2010.

"ATE destaca cambios en la cobertura periodística de Canal 10", Agencia Digital de Noticias, 2 de mayo de 2014. http://adnrionegro.com.ar

- Normativas consultadas:

Ley Provincial n 1952

Ley Provincial n 3276

Ley Nacional $n^{\circ} 23696$

Resolución 1622 del Ministerio de Hacienda de Río Negro 